\title{
Use of glutathione during white wine production - impact on S-off-flavors and sensory production
}

\author{
Pascal Wegmann-Herr ${ }^{\mathrm{a}}$, Sebastian Ullrich, Hans-Georg Schmarr, and Dominik Durner \\ Institute for Viticulture and Oenology, DLR Rheinpfalz, Breitenweg 71, 67435 Neustadt/W, Germany
}

\begin{abstract}
Recently two OIV resolutions (OENO 445-2015 and OENO 446-2015) were adopted, defining the use of glutathione (GSH) up to a maximum level of $20 \mathrm{mg} / \mathrm{L}$ in must and wine. Various studies have shown the benefits of GSH addition, especially in Sauvignon blanc wines. On the other hand, the formation of hydrogen sulfide $\left(\mathrm{H}_{2} \mathrm{~S}\right)$ and other S-off-flavors favored by GSH addition are reported. To investigate the effect of glutathione on the color development, the sensory expression and the formation of sulfide off-flavors, Riesling, Sauvignon Blanc and Chardonnay grapes were processed under different conditions and musts were obtained with different phenolic contents. By the addition of GSH as a pure substance or the use of GSHrich inactivated yeast preparations, the GSH concentration in the musts was varied. Bottled wines showed generally lower GSH levels than the corresponding musts. However, higher GSH concentrations after yeast aging could be determined, which may explain increased protection against oxidation during further storage. The sensory analysis after bottling showed that the fruity character of Riesling and Sauvignon blancs was enhanced at moderate GSH addition. Overuse of GSH in musts with low phenolic content, however, can lead to sensory perceptible S-off-flavors in the later wines.
\end{abstract}

\section{Introduction}

The use of $20 \mathrm{mg} / \mathrm{L}$ glutathione (GSH) has been legitimated in 2015 by the OIV [1,2]. Oxidative browning of must and wine is said to be prevented, aroma compounds, such as volatile thiols, are preserved, and the development of ageing flavours, such as sotolon and 2- aminoacetophenone, is impeded [3]. Researchers have proposed the hydroxycinnamic acid to GSH ratio (HGR) as an indicator of oxidation susceptibility of must. It was shown that lower ratios yielded lighter musts [4]. In contrast to the advantages of GSH, other researchers found that GSH can foster the formation of $\mathrm{H}_{2} \mathrm{~S}$ and other sulfide off-flavours during fermentation [5]. Besides the proposed protective effect against chemical oxidation resulting in the glutathione disulfide (GSSG) [6] the protective effects against enzymatic oxidation during grape processing with subsequent formation of the Grape Reaction Products (GRP1 and GRP2) are reported [7]. On the other hand glutathione is affecting the yeast metabolism, supporting the detoxification of the cells and a major role in the $\mathrm{S}-$, and $\mathrm{N}$-metabolism is attributed to glutathione [8].

\section{Materials and methods}

\subsection{Experimental winemaking}

In vintage 2015 in total 70 wines in repetition (140 fermentations) have been produced in the experimental pilot winery of the DLR Rheinpfalz, Institute for viticulture and oenology, under controlled conditions. By applying different treatments the ratio of hydroxycinnamic acid to GSH was modulated prior fermentation using

a e-mail: pascal.wegmann-herr@dlr.rlp.de
Chardonnay, Sauvignon blanc and Riesling grapes of the palatinate region. The GSH concentration was furthermore varied by direct GSH addition prior fermentation $(10 \mathrm{mg} / \mathrm{L}$ or $20 \mathrm{mg} / \mathrm{L}$ ) or GSH-enriched inactive dry yeast (IDY) at $40 \mathrm{~g} / \mathrm{hL}$ either before or after fermentation. The resulting wines were either racked of the lees or submitted to sur lies aging for 4 month. The different treatments are given in Table 1.

\subsection{Chemical and sensory analysis}

High performance liquid chromatography (HPLC) analysis was used to quantify both hydroxycinnamic acids (including GRP) and glutathione. Whilst GRP, caffeic acid, p-coumaric acid, ferulic acid and caftaric acid could be determined at a wavelength of $320 \mathrm{~nm}$ after separating the sample with a RP-18 column (Phenomenex Gemini NX), a derivatization step was necessary to detect glutathione. After adding o-phthalaldehyde and ethanolamine to the wine sample, the glutathione formed a fluorescent imidazole derivative used for its quantification after separating the sample with a polar embedded RP-18 column (Phenomenex Synergi Fusion- RP). Sulfide offflavors were monitored using solid phase microextraction followed by gas chromatography coupled with a pulsed flame photometric detector (HS-SPME- GC- PFPD). Furthermore, a stable isotope dilution assay (SIDA) without any mass-selective detection was applied for quantification using isotopic (deuterated) internal standard compounds synthesised in-house. Separation between labelled and non-deuterated compounds could be realized with a $60 \mathrm{~m}$ fused silica column $(0.32 \mathrm{~mm}$ i.d. $)$ coated with an apolar stationary phase of $100 \%$ dimethyl polysiloxane (1 $\mu \mathrm{m}$ film thickness), utilizing the inverse isotope effect

(c) The Authors, published by EDP Sciences. This is an Open Access article distributed under the terms of the Creative Commons Attribution License 4.0 (http://creativecommons.org/licenses/by/4.0/). 
Table 1. Applied variations during experimental winemaking vintage 2015.

\begin{tabular}{|c|c|c|c|c|c|c|}
\hline \multicolumn{7}{|c|}{ technological / oenological variation } \\
\hline variety & $\begin{array}{l}\text { ascorbic acid } \\
\text { must }(100 \mathrm{mg} / \mathrm{L})\end{array}$ & $\begin{array}{c}\text { ascorbic acid } \\
\text { wine }(100 \mathrm{mg} / \mathrm{L})\end{array}$ & sur lies & $\begin{array}{c}\text { skin } \\
\text { contact }(8 \mathrm{~h})\end{array}$ & free run & $\begin{array}{l}\text { press } \\
\text { fraction }\end{array}$ \\
\hline Riesling I $(n=20)$ & $\mathrm{x}$ & $\mathrm{x}$ & $\mathrm{x}$ & & & \\
\hline Riesling II ( $\mathrm{n}=20)$ & & & & $\mathrm{x}$ & $\mathrm{x}$ & $\mathrm{x}$ \\
\hline Sauvignon blanc $(\mathrm{n}=20)$ & $\mathrm{x}$ & $\mathrm{x}$ & $\mathrm{x}$ & & & \\
\hline Chardonnay $(n=10)$ & & $\mathrm{x}$ & $\mathrm{x}$ & & & \\
\hline
\end{tabular}

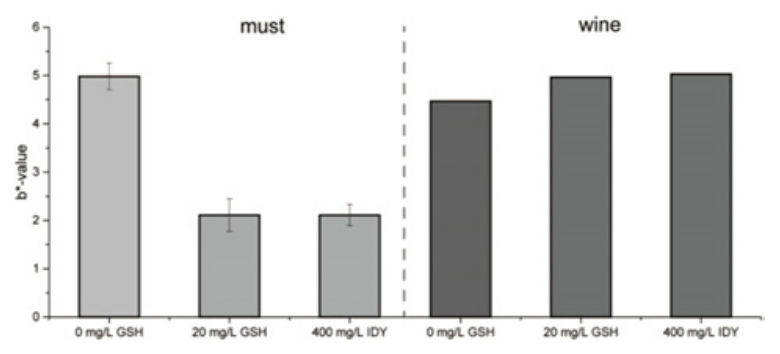

Figure 1. b*-values (yellow color) in Sauvignon blanc musts and wines for different GSH additions.

[9]. The extraction step was carried out by using a 50/30 $\mu \mathrm{m}$ DVB/CAR/PDMS fibre from Supelco which was $2 \mathrm{~cm}$ in length. Analysis of 3- Mercaptohexanol (3-MH) was done by Sarco (Bordeaux, France). Descriptive sensory analysis was performed by a trained panel of 15 judges; all the wines were tasted in duplicates in a randomized order.

\section{Results and discussion}

Following some of the results are shown and discussed exemplarily.

Adding GSH or IDY, respectively, to fresh grape juice yielded lighter musts which is in accordance with the hypothesis mentioned earlier. However, no difference in yellow colour was observed in the bottled wines. Obviously, GSH was not able to prevent oxidative browning during winemaking (Fig. 1). Compared to the protective effect of ascorbic acid against must browning the addition of GSH was more powerful (data not shown).

The ability of GSH to preserve 3-Mercaptohexanol (3- MH) in Sauvignon blanc wines is shown in Fig. 2. For storage trials all variants haven been pooled according to the GSH modalities and then analyzed for their 3-MH concentration. Both, GSH and IDY addition to the must resulted in higher 3-MH contents in the young wines. However, the addition of IDY after fermentation does lead to higher concentrations ranging on the same level as the control. This suggests that the GSH addition prior fermentation might influence the yeast metabolism increasing the capacity of the yeasts to transform odorless precursors into the potent aroma compound.

On the other hand, as it can be seen in Fig. 3, the addition of GSH either as pure substance or in form of IDY can lead to the formation of hydrogen sulfide. In case of this Riesling the control variant was vinified without any skin contact or press fractions showing a HGR of 2.74 , therefore to be considered as medium sensitive to oxidation. The yeast assimilable $\alpha$-amino nitrogen

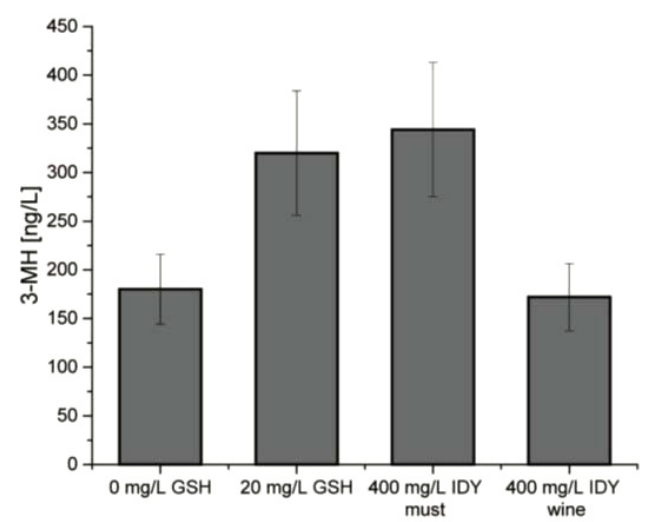

Figure 2. Influence of GSH on the 3-Mercaptohexanol (3-MH) concentration in Sauvignon blanc wines.

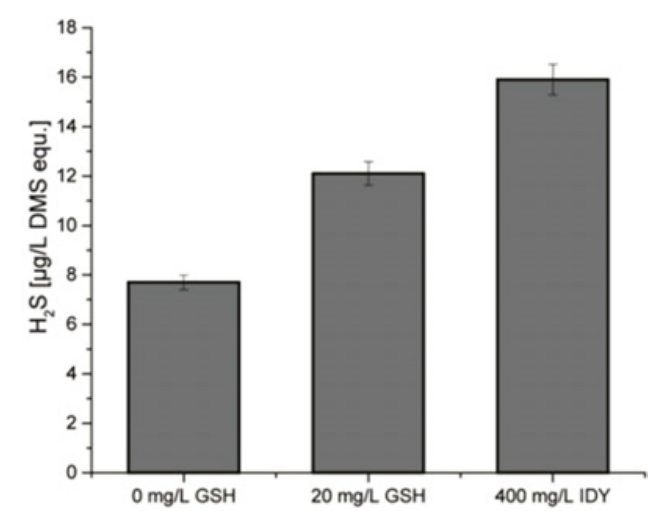

Figure 3. Influence of GSH on the formation of hydrogen sulfide (H2S) in Riesling wines.

of $92 \mathrm{mg} / \mathrm{L}$ NOPA was very low. There might be two explanations for the observed increase in $\mathrm{H}_{2} \mathrm{~S}$ formation due to GSH addition. First under $\mathrm{N}$-stress the yeast might have metabolized the added GSH with subsequent $\mathrm{H}_{2} \mathrm{~S}$ production, second the free sulfhydryl moiety of $\mathrm{GSH}$ can react with $o$-quinones evolving from phenolic compounds. Hence, these quinones loose their ability to trap mercaptans, which are responsible for sulfide offflavors.

Regarding the sensory impact, adding GSH as a pure substance prior fermentation significantly increased the intensity of sulfide off-flavors in Sauvignon blanc wines. At the same time, these wines were rated with the highest colour intensity. The control as well as the IDY treated wines appeared to have stronger fruity and banana intensities. A conclusive effect of GSH additions on other attributes was not observed (Fig. 4). 


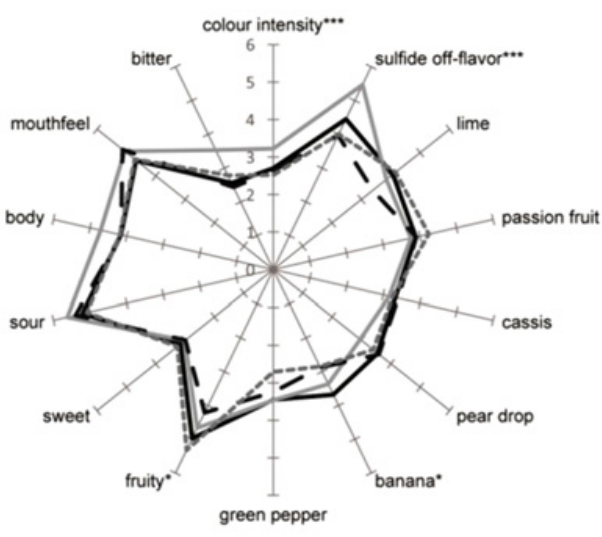

- control $\quad 20 \mathrm{mg} / \mathrm{L} \mathrm{GSH} \quad-\quad-400 \mathrm{mg} / \mathrm{L}$ IDY must $\quad----400 \mathrm{mg} / \mathrm{L}$ IDY wine

Figure 4. Sensory profile of Sauvignon blanc wines with different GSH additions. ( $\left.{ }^{*} \mathrm{p}<0.05,{ }^{* *} \mathrm{p}<0.01,{ }^{* * *} \mathrm{p}<0.001\right)$.

This contradicting result compared to some published positive effects regarding the impact of GSH during Sauvignon blanc production might be explained with the synergistic effect of ascorbic acid addition to the young wines. Here $100 \mathrm{mg} / \mathrm{L}$ ascorbic acid had been added to the wines prior the first $\mathrm{SO}_{2}$ addition. But even if the perception of sulphide off-flavors can be explained by the reductive conditions due to combined application of GSH and ascorbic acid the increase in colour intensity is inconsistent. It is well known that wines treated very reductive till bottling are very sensitive to oxygen uptake and tend therefore to faster oxidative browning whereby the sensory perception of sulphide off-flavors remains stable. Regarding all the results of the descriptive sensory analysis of all varieties no pattern of a predictable sensory influence of GSH addition could be detected. In some cases GSH addition showed no effect at all, led in other cases to an increased perception of fruity attributes such as lime and in most cases to reduced fruitiness due to stronger offflavor expression. No systematic difference to classify type of product (pure GSH or IDY) or time of addition could be observed but the tendency of $20 \mathrm{mg} / \mathrm{L}$ GSH added to must with low phenolic content leading to sensory perceptible S-off-flavors can be stated.

\section{Conclusion}

Using GSH and IDY in winemaking prevented the oxidative browning of musts, but this observation was not related to the colour of the later wines. Desirable aroma compounds, such as 3-MH, were preserved by GSH addition to musts, but at the same time mercaptan trapping seemed to be inhibited due to the formation of GSH-phenol adducts. As a consequence, wines showed higher concentrations in sulfide off-flavors. No predictable benefits on sensory characteristics of young Riesling, Chardonnay and Sauvignon blanc wines were observed. More research is necessary to investigate GSH effects with regard to different enological practises and for longer term storage scenarios.

This work was supported by the Federal Ministry for Economic Affairs and Energy (via AiF) and the FEI (Forschungskreis der Ernährungsindustrie e.V., Bonn) Project AiF 18645 N.

Special thanks to Benedikt Grein and Florian Schraut for help during the experimental winemaking.

\section{References}

[1] OIV-OENO 445-2015

[2] OIV-OENO 446-2015

[3] V. Vamakis and I.G. Roussis. Food Chem. 57 (1996) 419-422

[4] W. du Toit, J. Marais, I.S. Pretorius and M. du Toit. S. Afr. J. Enol. Vitic. 27, 76-94 (2006)

[5] M. Ugliano, M. Kwiatkowski, S. Vidal, D. Capone, T. Siebert, J.B. Dieval, O. Aagaard and E.J. Waters. J. Agric. Food Chem. 59, 2564-2572 (2011)

[6] E.C. Kritzinger, F.F. Bauer and W. J. du Toit. J.Agric.Food Chem. 61, 269-277 (2013)

[7] E.C. Kritzinger, W.J. du Toit and M.A. Stander. Food Addit. Conta. Part A. 30, 80-92 (2013)

[8] A. Pastore, G. Federici, E. Bertini and F. Piemonte. Clin. Chim. Acta. 333, 19-39 (2003)

[9] H.G. Schmarr, P. Slabizki, S. Müntnich, C. Metzger, E. Gracia-Moreno. J. Chromatogr. A. 1270, 310-317 (2012) 